\title{
The effect of pressure on the structure of $\mathrm{NiAl}_{2} \mathrm{O}_{4}$
}

\author{
Itzhak Halevy $^{1,4}$, Danut Dragoi ${ }^{1}$, Ersan Üstündag ${ }^{1,5}$, Alan F Yue ${ }^{1}$ \\ Elizabeth $\mathrm{H}$ Arredondo ${ }^{2}$, Jingzhu $\mathrm{Hu}^{3}$ and Maddury S Somayazulu ${ }^{3}$ \\ ${ }^{1}$ Department of Materials Science, California Institute of Technology, Pasadena, CA 91125, USA \\ 2 Division of Geological and Planetary Sciences, California Institute of Technology, Pasadena, \\ CA 91125, USA \\ ${ }^{3}$ Geophysical Laboratory of Carnegie Institution of Washington, Washington, DC 20015, USA \\ E-mail: ersan@caltech.edu.
}

Received 24 June 2002

Published 25 October 2002

Online at stacks.iop.org/JPhysCM/14/10511

\begin{abstract}
$\mathrm{NiAl}_{2} \mathrm{O}_{4}$ is known to transform from a normal spinel, $\left(\mathrm{Ni}^{2+}\right)\left[\mathrm{Al}_{2}^{3+}\right] \mathrm{O}_{4}$, to an inverse spinel, $\left(\mathrm{Al}^{3+}\right)\left[\mathrm{Ni}^{2+} \mathrm{Al}^{3+}\right] \mathrm{O}_{4}$, and vice versa. In this process, the larger $\mathrm{Ni}^{2+}$ ions which occupy the tetrahedral (8a) sites in normal spinel move to the octahedral (16d) sites in inverse spinel while half of the smaller $\mathrm{Al}^{3+}$ ions move in the opposite direction. The extent of this move is measured by the disorder or inversion parameter, $I$ (the fraction of tetrahedral sites occupied by the Al ions; $I=0$ for normal spinel and $I=1$ for inverse spinel). Previous studies suggest that the lattice constant of spinel can decrease as the disorder parameter increases to better accommodate the Ni ions. In situ neutron diffraction studies performed by us indicate that this process is also occurring during the reduction of $\mathrm{NiAl}_{2} \mathrm{O}_{4}$ to $\mathrm{Ni}$ and $\mathrm{Al}_{2} \mathrm{O}_{3}$. It is possible that the compressive residual stresses generated during reduction play a role in the structural evolution of $\mathrm{NiAl}_{2} \mathrm{O}_{4}$.

To systematically investigate the effect of pressure on the structure of $\mathrm{NiAl}_{2} \mathrm{O}_{4}$, X-ray diffraction studies at the X17 beamline of the National Synchrotron Light Source were performed. The pressure (up to $35 \mathrm{GPa}$ ) was applied via a diamond anvil cell and the experiments were conducted using a polychromatic x-ray beam. By comparing the relative intensities of certain spinel reflections that are sensitive to cationic disorder, a trend toward inverse spinel as a function of pressure was observed. The results are presented in comparison to previous studies on this material.
\end{abstract}

(Some figures in this article are in colour only in the electronic version)

\footnotetext{
${ }^{4}$ Permanent address: Physics Department, Negev Nuclear Research Centre, PO Box 9001, 84190 Beer-Sheva, Israel.

5 Author to whom any correspondence should be addressed. 


\section{Introduction}

A general formula for 2-3 oxide spinels is $\mathrm{AB}_{2} \mathrm{O}_{4}$, where $\mathrm{A}$ and $\mathrm{B}$ are divalent and trivalent cations, respectively $[1,2]$. In normal spinel the divalent cations occupy 8 tetrahedral interstices (8a) and the trivalent cations sit in 16 octahedral (16d) sites. The structure in this case is denoted as $\mathrm{AB}_{2} \mathrm{O}_{4}$. In inverse spinel, (B) $[\mathrm{AB}] \mathrm{O}_{4}$, all 8 divalent cations together with 8 trivalent ones occupy 16 octahedral positions while the remaining 8 trivalent cations move to 8 tetrahedral sites. In spinel structure, the oxygen ions occupy the 32e sites and are arranged in an almost cubic close-packed manner. The unit cell contains eight formula units and has the cubic space group $\mathrm{Fd} 3 \mathrm{~m}$. Many spinels, including $\mathrm{NiAl}_{2} \mathrm{O}_{4}$, have structures that fall in between the two extremes. The changes in the cationic sublattice are quantified by the disorder or inversion parameter, $I$ (the fraction of tetrahedral sites occupied by the trivalent ions). In other words, $I=0$ for normal spinel and $I=1$ for inverse spinel. Usually at high temperatures, spinels tend towards the completely random distribution where $I=2 / 3$, i.e., $\left(\mathrm{A}_{1 / 3} \mathrm{~B}_{2 / 3}\right)\left[\mathrm{A}_{2 / 3} \mathrm{~B}_{4 / 3}\right] \mathrm{O}_{4}$.

The relative ease with which its cationic sublattice can be modified (due to fast cationic self-diffusion) has led to many structural studies on $\mathrm{NiAl}_{2} \mathrm{O}_{4}$. Here the two most recent ones are cited: [1, 2]. The reader is referred to [2] for a more detailed review. Almost all of these studies used $\mathrm{x}$-ray powder diffraction (XRD) for structure analysis. Specimens were usually annealed at high temperatures and then quenched to room temperature assuming that the high-temperature structure would be conserved ('frozen in'). These studies showed that Ni spinel tended to become less inverse at higher temperatures approaching the 'random' case with $I=2 / 3$. They also noticed relationships between the inversion, oxygen and lattice parameters. Specifically, the lattice parameter decreased as the inversion parameter increased. A similar inverse relationship was also observed between the inversion and oxygen parameters. These observations can be explained by the fact that the $\mathrm{Ni}^{2+}$ ions are much larger than $\mathrm{Al}^{3+}$ ions. As a result, the $\mathrm{Ni}^{2+}$ ions can fit 'more easily' in the larger octahedral (16d) sites, and when they move from the smaller tetrahedral (8a) sites into the $16 \mathrm{~d}$ sites (as spinel becomes more inverse), the lattice relaxes, leading to decreases in the oxygen and lattice parameters.

\section{Neutron powder diffraction results}

Our interest in the structure of $\mathrm{Ni}$ spinel was motivated by our previous studies of its reduction to $\mathrm{Ni}$ and $\mathrm{Al}_{2} \mathrm{O}_{3}$ [3-5]. This reaction is accompanied by a volume shrinkage (up to $18 \%$ ) and can lead to residual stress generation. In previous neutron powder diffraction (NPD) work [35], this reaction was monitored in situ to elucidate the evolution of strains and phases. It was seen that substantial changes in the spinel lattice constant could occur in some specimens (figure 1(a)) pointing to the possibility of significant residual strain/stress generation during reduction. The NPD specimens were cylinders in which the progress of the reaction from the surface inward would lead to an enclosed unreduced $\mathrm{NiAl}_{2} \mathrm{O}_{4}$ region surrounded by a $\mathrm{Ni}-\mathrm{Al}_{2} \mathrm{O}_{3}$ composite layer. The shrinkage of this outside layer (combined with the constraint imposed on it by the unreduced spinel in the middle) could lead to compressive stresses/strains in the spinel. The data shown in figure 1(a) seemed to support this hypothesis since a progressively increasing compressive 'strain' was measured in the spinel.

Unfortunately, a second observation obtained from the NPD data complicated the above interpretation. As shown in figure 1(b), the Rietveld refinement of the NPD data yielded a progressive transformation of $\mathrm{NiAl}_{2} \mathrm{O}_{4}$ towards inverse spinel. The equilibrium value of $I$ was measured to be around 0.8 at $1200^{\circ} \mathrm{C}$ in previous studies $[1,2] . I=0.8$ was approximately the value obtained at the beginning of the reduction (figure 1(b)); however, its later change towards 1.0 seemed to be related to the reduction reaction, and more specifically the conceivable 

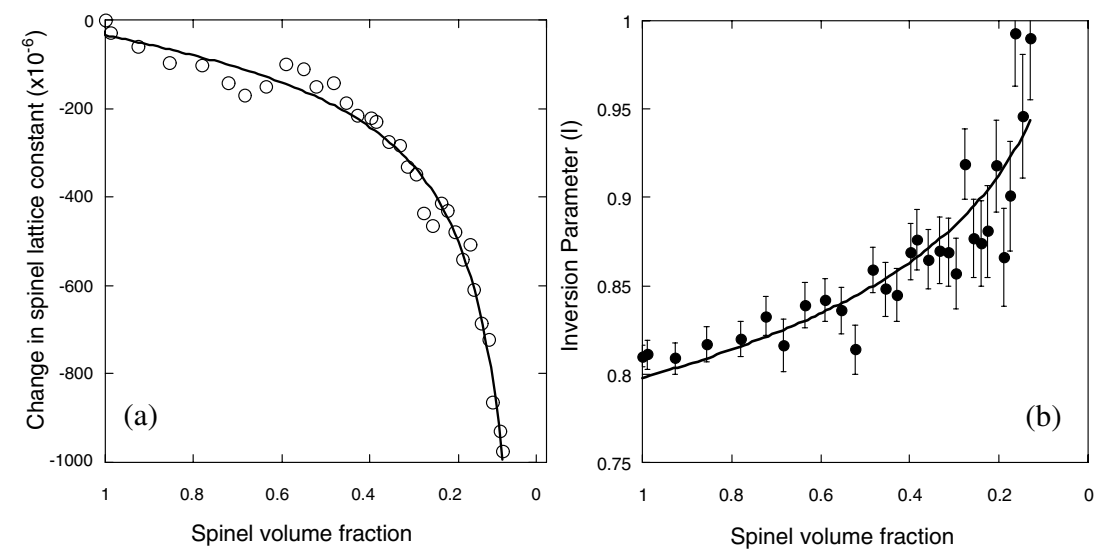

Figure 1. In situ NPD results from the reduction of Ni spinel at $120{ }^{\circ} \mathrm{C}$ [3-5]. (a) The evolution of the spinel lattice parameter as a function of unreduced spinel volume fraction (and rough reduction time); (b) the change in the inversion parameter of spinel. Fitting curves are added to both plots to guide the eye.

compressive stresses generated during its progress. To clarify the effect of pressure on the structure of $\mathrm{NiAl}_{2} \mathrm{O}_{4}$, several high-pressure experiments were conducted using a diamond anvil cell and employing XRD. Some preliminary results are presented and discussed in this article.

\section{Experimental procedure}

$\mathrm{NiAl}_{2} \mathrm{O}_{4}$ was processed by reacting stoichiometric mixtures of $\mathrm{Al}_{2} \mathrm{O}_{3}$ and $\mathrm{NiO}$ in air at $1550{ }^{\circ} \mathrm{C}$ for $48 \mathrm{~h}$. The partly sintered compacts were ground to powder, which was then sieved to -325 mesh size $(<44 \mu \mathrm{m})$. The samples were stoichiometric within the experimental error (as determined by electron microprobe analysis). There was no significant loss of Ni during the high-temperature annealing. To attain the equilibrium structure of spinel, the powders were annealed again at various temperatures following the guidelines given in the literature [2]. After annealing, the samples were pulled out of the furnace quickly to induce a fast cooldown to room temperature (within several minutes). In this article, the results obtained from the $\mathrm{NiAl}_{2} \mathrm{O}_{4}$ powders annealed at $1100^{\circ} \mathrm{C}$ for $60 \mathrm{~h}$ are reported. To confirm that the $1100^{\circ} \mathrm{C}$ structure was maintained after cooldown, room temperature XRD measurements were performed using a Siemens D500 diffractometer with $\mathrm{Cu} \mathrm{K} \alpha$ radiation. The data were analysed using a Rietveld code [6]. The inversion parameter obtained from Rietveld analysis $(I \sim 0.82)$ was reasonably close to the value reported in the literature $[1,2]$ for $1100^{\circ} \mathrm{C}$ anneals $(\sim 0.81)$. It should be noted that anneals conducted at temperatures below $800^{\circ} \mathrm{C}$ yield an $I$-value of close to 1.0 [1, 2].

High-pressure (quasi-hydrostatic) XRD experiments were carried out in a 'Tel-Aviv'type diamond anvil cell with $600 \mu \mathrm{m}$ culets. The pressure calibration was done with ruby and platinum while $\mathrm{Si}$ oil was the pressure medium in a $250 \mu \mathrm{m}$ diameter stainless steel gasket. These experiments were conducted in ambient temperature at the X17C beamline of the National Synchrotron Light Source (NSLS). In this process, energy dispersive (EDS) data generated by a polychromatic x-ray beam were collected with a Ge detector at a fixed Bragg angle $\left(2 \theta=13^{\circ}\right)$. The pressure distribution inside the sampling volume was checked and was determined as varying by less than $5 \%$. Typical data collection time was around $5 \mathrm{~min}$. 


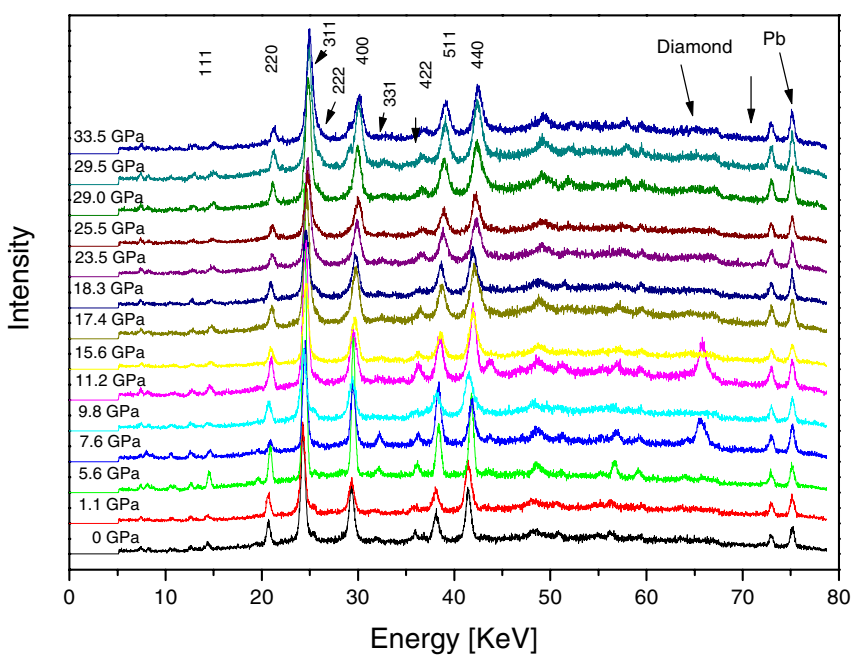

Figure 2. The effect of pressure on the EDS x-ray pattern of $\mathrm{NiAl}_{2} \mathrm{O}_{4}$ at ambient temperature. Major spinel reflections are indexed. A systematic shift towards higher energy (i.e., lower $d$ spacing) is observed in $\mathrm{NiAl}_{2} \mathrm{O}_{4}$ due to the compression of its lattice.

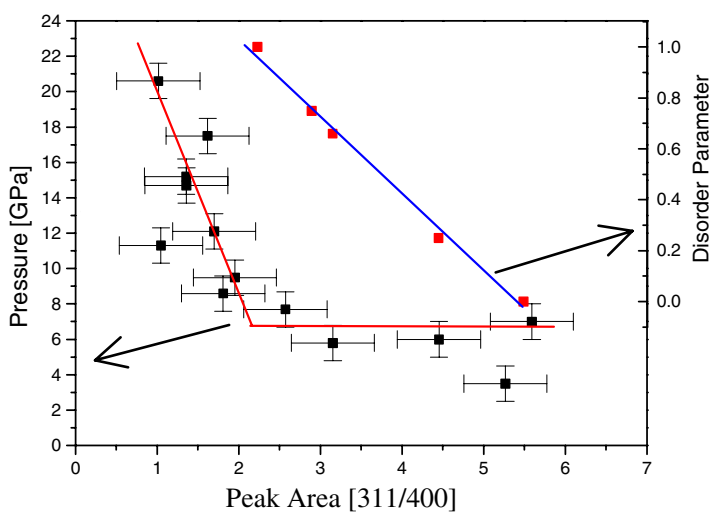

Figure 3. The variation of the relative intensities of the (311) and (400) reflections of $\mathrm{NiAl}_{2} \mathrm{O}_{4}$ as a function of pressure. The lines were added to the experimental data to guide the eye. The 'Crystallographica' prediction is shown on the right axis.

\section{Results and discussion}

The pressure/x-ray energy data of the $\mathrm{NiAl}_{2} \mathrm{O}_{4}$ spinel are shown in figure 2 for the range of 0-33.5 GPa. Note that the escape peaks are ignored in these patterns. They usually occur at energies about $9.8 \mathrm{keV}$ lower than the original peak in each case.

The data shown in figure 2 are currently being analysed with the Rietveld method. In the meantime, single-peak fitting was performed on some reflections of $\mathrm{Ni}$ spinel. Of these, (400) is insensitive to changes in the cationic sublattice, while (311) is the most sensitive. This was determined by simulating spinel diffraction patterns as a function of $I$ using commercial software (Crystallographica) and the results are shown in figure 3. A comparison of the relative intensities of these two reflections (figure 3 ) as revealed by the experimental data shows that there is systematic change towards inverse spinel as a function of applied pressure. This 


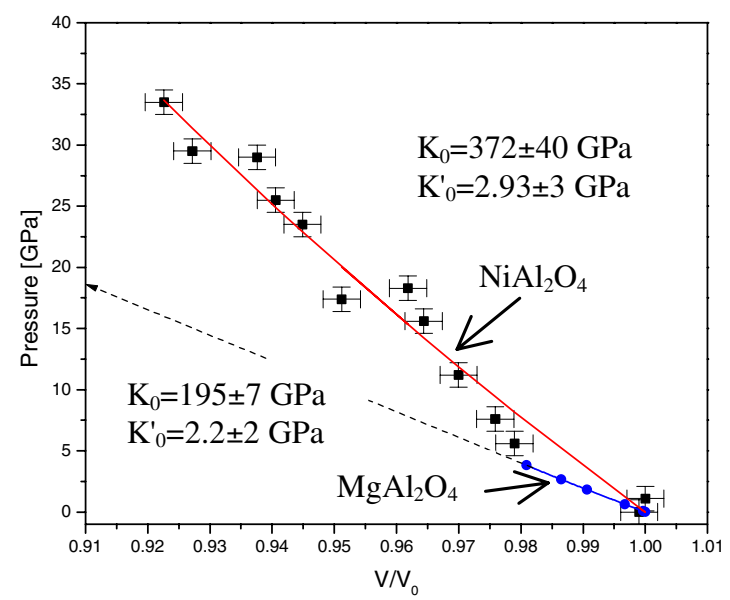

Figure 4. The pressure-unit-cell-volume relationship for $\mathrm{NiAl}_{2} \mathrm{O}_{4}$. A Birch-Murnaghan equation of state was fitted to the data. The $\mathrm{MgAl}_{2} \mathrm{O}_{4}$ data [9] were added for comparison.

change seems to stop around $10 \mathrm{GPa}$ at which point the spinel is likely to be fully inverse. A further confirmation of this observation will only be possible after the Rietveld refinement is completed and will be reported in a future publication.

This is the first time that the effect of pressure on the cationic partitioning in $\mathrm{NiAl}_{2} \mathrm{O}_{4}$ has been studied experimentally. Preliminary data (figure 3) suggest that $\mathrm{NiAl}_{2} \mathrm{O}_{4}$ can transform under pressure and become an inverse spinel. The only other similar study on $\mathrm{NiAl}_{2} \mathrm{O}_{4}$ was a theoretical investigation using interionic potential calculations [7]. It showed that the inversion parameter of $\mathrm{NiAl}_{2} \mathrm{O}_{4}$ could indeed increase under pressure. For instance, this study predicted that at $25^{\circ} \mathrm{C}, I=0.992$ at ambient pressure and $I=1.0$ at $10 \mathrm{GPa}$. Similarly, $I$ was calculated to increase from 0.827 (ambient pressure) to $0.857(10 \mathrm{GPa})$ at $1100{ }^{\circ} \mathrm{C}$ [7]. Our preliminary results then seem to confirm the NPD observations (figure 1) in that the structural evolution during the reduction of $\mathrm{NiAl}_{2} \mathrm{O}_{4}$ is probably due to compressive residual stresses generated during reduction.

Another result of the high-pressure experiments is the equation of state of $\mathrm{NiAl}_{2} \mathrm{O}_{4}$. The pressure-volume curve shown in figure 4 allows the calculation of the bulk modulus of this material using the Birch-Murnaghan analysis [8]. The pressure-volume curve (figure 4) shows about $8 \%$ reduction in unit-cell volume at $33.5 \mathrm{GPa}$. Fitting the dependence of the unit-cell volume, $V$, on pressure to a Birch-Murnaghan equation of state yielded the zeropressure bulk modulus, $K_{0}=372 \pm 40 \mathrm{GPa}$ and the pressure derivative for the bulk modulus, $K_{0}^{\prime}=2.9 \pm 3$. The $K_{0}$-value compares favourably with the results of ultrasonic measurements of the elastic constants of $\mathrm{NiAl}_{2} \mathrm{O}_{4}$ using solid polycrystalline samples. These measurements produced a Young's modulus of about $345 \mathrm{GPa}$ and a Poisson's ratio of about 0.36 . There is some uncertainty in these values since the exact amount of porosity in the samples could not be determined to a high precision. Nevertheless, the bulk modulus obtained from the ultrasonic data is about $410 \mathrm{GPa}$, approximately in the same range as given by the highpressure data. It is interesting to note that a similar high-pressure experiment on the more common $\mathrm{MgAl}_{2} \mathrm{O}_{4}$ spinel produced a much lower value for the zero-pressure bulk modulus of that material $\left(K_{0} \sim 195 \mathrm{GPa}\right)[9]$. 


\section{Conclusions}

The preliminary results of high-pressure XRD experiments conducted at NSLS using a diamond anvil cell suggest that pressure forces $\mathrm{NiAl}_{2} \mathrm{O}_{4}$ spinel to become more inverse. At a pressure of $\sim 10 \mathrm{GPa}$ the change ceases, probably because the $\mathrm{NiAl}_{2} \mathrm{O}_{4}$ structure is already fully inverse. These observations were obtained by comparing the relative intensities of the (311) and (400) reflections of $\mathrm{NiAl}_{2} \mathrm{O}_{4}$. The former is the reflection most sensitive to changes in the cationic sublattice of $\mathrm{NiAl}_{2} \mathrm{O}_{4}$, while the latter is completely insensitive to these. A more quantitative description of the effect of pressure on the $\mathrm{NiAl}_{2} \mathrm{O}_{4}$ structure is expected after the completion of the Rietveld analyses of the EDS XRD data. The preliminary results, however, do support the previous NPD results in that the reduction of $\mathrm{NiAl}_{2} \mathrm{O}_{4}$ seems to generate compressive residual stresses which cause its transformation to a more inverse spinel. The other important conclusion of the present study is that no other pressure-induced phase transformations are present in $\mathrm{NiAl}_{2} \mathrm{O}_{4}$ at pressures up to $34 \mathrm{GPa}$. Finally, the bulk modulus of $\mathrm{NiAl}_{2} \mathrm{O}_{4}$ was also calculated from the high-pressure data using a Birch-Murnaghan analysis and its value ( $\sim 370 \mathrm{GPa})$ was found to be similar to that obtained by independent ultrasonic measurements on solid specimens.

\section{Acknowledgment}

The high-pressure x-ray data were collected at the National Synchrotron Light Source (NSLS) which is supported by the US Department of Energy under contract no DE-AC02-76CH00016.

\section{References}

[1] Mocala K and Navrotsky A 1989 J. Am. Ceram. Soc. 72 826-32

[2] Roelofsen J N, Peterson R C and Raudsepp M 1992 Am. Mineral. 77 522-8

[3] Üstündag E, Clausen B and Bourke M A M 2000 Appl. Phys. Lett. 76 694-6

[4] Üstündag E, Woodman R H, Hanan J C, Clausen B, Hartmann T and Bourke M A M 1999 Ceram. Trans. 94537

[5] Clausen B, Üstündag E and Bourke M A M 2001 Adv. X-Ray Anal. 4432

[6] Larson A C and von Dreele R B 1986 GSAS — General Structure Analysis System Los Alamos National Laboratory Report LAUR86-748

[7] Giusta A D and Ottonello G 1993 Phys. Chem. Minerals $20228-41$

[8] Birch F 1986 J. Geophys. Res. 91 4949-54

[9] Kruger M B, Nguyen J H, Caldwell W and Jeanloz R 1997 Phys. Rev. B 56 1-4 